\title{
Association between ERCC1 and TS mRNA levels and disease free survival in colorectal cancer patients receiving oxaliplatin and fluorouracil (5-FU) adjuvant chemotherapy
}

Sheng Li $i^{*}$, Liangjun Zhu', Li Yao ${ }^{2}$, Lei Xia ${ }^{3}$ and Liangxi Pan ${ }^{1}$

\begin{abstract}
Background: Aim was to explore the association of ERCC1 and TS mRNA levels with the disease free survival (DFS) in Chinese colorectal cancer (CRC) patients receiving oxaliplatin and 5-FU based adjuvant chemotherapy.

Methods: Total 112 Chinese stage II-III CRC patients were respectively treated by four different chemotherapy regimens after curative operation. The TS and ERCC1 mRNA levels in primary tumor were measured by real-time RT-PCR. Kaplan-Meier curves and log-rank tests were used for DFS analysis. The Cox proportional hazards model was used for prognostic analysis.

Results: In univariate analysis, the hazard ratio (HR) for the mRNA expression levels of TS and ERCC1 (logTS: HR $=0.820$, $95 \% \mathrm{Cl}=0.600-1.117, P=0.210 ; \log E R C C 1: \mathrm{HR}=1.054,95 \% \mathrm{Cl}=0.852-1.304, P=0.638)$ indicated no significant association of DFS with the TS and ERCC1 mRNA levels. In multivariate analyses, tumor stage (IIlc: reference, $P=0.083 ;$ llb: $\mathrm{HR}=0.240,95 \% \mathrm{Cl}=0.080-0.724, P=0.011$; $\| \mathrm{c}: \mathrm{HR}<0.0001, P=0.977$; Illa: $\mathrm{HR}=0.179,95 \% \mathrm{Cl}=0.012-2.593$, $P=0.207$ ) was confirmed to be the independent prognostic factor for DFS. Moreover, the Kaplan-Meier DFS curves showed that TS and ERCC1 mRNA levels were not significantly associated with the DFS (TS: $P=0.264$; ERCC1: $P=0.484)$.

Conclusion: The mRNA expression of ERCC1 and TS were not applicable to predict the DFS of Chinese stage II-III CRC patients receiving 5-FU and oxaliplatin based adjuvant chemotherapy.
\end{abstract}

Keywords: Colorectal cancer, ERCC1, TS, Real-time PCR, Adjuvant chemotherapy

\section{Background}

Colorectal cancer (CRC) is the third most common cancer worldwide and has a high mortality rate [1]. About 608,000 deaths from CRC are estimated worldwide, accounting for $8 \%$ of all cancer deaths [2,3]. Surgery is the most common treatment for CRC, yet prognosis remains poor [4]. As a result, considerable interest has concentrated on chemotherapy after surgery, such as oxaliplatin or 5-fluorouracil (5-FU)-based adjuvant chemotherapy $[5,6]$. The $5-\mathrm{FU}$ is an analogue of uracil with a fluorine atom at the C-5 position in place of hydrogen, which disrupts RNA synthesis and the action of thymidylate

\footnotetext{
* Correspondence: shengli34t@hotmail.com

'Oncology, Jiangsu Tumor Hospital, NO.42 bai zi ting, Nanjing 210000, China Full list of author information is available at the end of the article
}

synthase by converting to several active metabolites: fluorodeoxyuridine monophosphate (FdUMP), fluorodeoxyuridine triphosphate (FdUTP) and fluorouridine triphosphate (FUTP) [7]. It was reported that 5-FU-based chemotherapy was a safe and effective treatment for elderly patients with advanced CRC [8]. Oxaliplatin is a platinum-based drug that has demonstrated antitumor activities in CRC both in vitro and in vivo [9]. It was reported that oxaliplatin based chemotherapy could significantly increase the progression-free survival in patients with metastatic CRC [10]. Moreover, the better efficacy and safety of oxaliplatin combined with 5-FU as first-line chemotherapy for elderly patients with metastatic CRC has been proved [11]. However, there is no predictive factor for efficacy of these treatments. 
The ERCC1 (encodes excision cross-complementing 1) gene codes for a nucleotide excision repair protein involved in the repair of radiation and chemotherapyinduced DNA damage [12]. It has been reported that the gene polymorphism of $E R C C 1$ at codon 118 was a predictive factor for the tumor response to oxaliplatin/5-FU combination chemotherapy in patients with advanced CRC [13]. Furthermore, thymidylate synthase (TS), as a target enzyme of $5-\mathrm{FU}$, is associated with response to 5 -FU in human colorectal and gastric tumors $[14,15]$. It was reported that TS genotyping could be of help in predicting toxicity to 5-FU-based chemotherapy in CRC patients [16]. However, little is known about the association between mRNA expression levels of ERCC1 and TS and clinical outcomes of oxaliplatin and 5-FU based adjuvant chemotherapy in Chinese people with CRC.

In this study, we investigated the association of ERCC1 and TS mRNA levels with the disease free survival (DFS) in Chinese CRC patients receiving oxaliplatin and 5-FU based adjuvant chemotherapy.

\section{Methods \\ Patients}

This study was carried out with the Institutional Ethics Committees approval and following the Chinese Medical Research Council guidelines. All participants gave their written informed consent prior to entering the study.

This is a prospective study. A total of 112 Chinese CRC patients who were treated at Jiangsu Tumor Hospital, China, from May 2005 to January 2010 were investigated in this study. Eligibility criterion was histological confirmation of stage II-III CRC after surgery according to the AJCC TNM classification [17].

\section{Chemotherapy treatment}

All the patients were treated with chemotherapy after curative operation. Four types of chemotherapy regimens were used for the treatment of CRC patients: i) the first one was the standard FOLFOX-4 consisting of 2-hour intravenous infusion of oxaliplatin $\left(85 \mathrm{mg} / \mathrm{m}^{2}\right)$ on day 1 , and 2-hour intravenous drip infusion of calcium folinate $\left(200 \mathrm{mg} / \mathrm{m}^{2}\right)$ on days $1-2$, followed by intravenous injection of 5 -FU $\left(400 \mathrm{mg} / \mathrm{m}^{2}\right)$ and continuous infusion of 5 -FU $\left(600 \mathrm{mg} / \mathrm{m}^{2}\right)$ lasting $22 \mathrm{~h}$ on days $1-2$, every 2 weeks; ii) the second one was the modified FOLFOX consisting of intravenous infusion of oxaliplatin $\left(130 \mathrm{mg} / \mathrm{m}^{2}\right)$ and 2-hour intravenous drip infusion of folinate calcium $\left(200 \mathrm{mg} / \mathrm{m}^{2}\right)$ on day 1 , followed by intravenous injection of $5-\mathrm{FU}\left(400 \mathrm{mg} / \mathrm{m}^{2}\right)$ and continuous infusion of 5 -FU $\left(1000 \mathrm{mg} / \mathrm{m}^{2}\right)$ over $24 \mathrm{~h}$ on days 1 to 3 , every 3 weeks; iii) the third one was oral XELOX consisting of 2-hour intravenous infusion of oxaliplatin $130 \mathrm{mg} /$ $\mathrm{m}^{2}$ on day 1 plus oral capecitabine $850 \mathrm{mg} / \mathrm{m}^{2}$ twice daily for 2 weeks in a 3-week cycle; iv) the fourth one was a conventional intravenous drip infusion including 2-hour intravenous infusion of oxaliplatin $130 \mathrm{mg} / \mathrm{m}^{2}$ on day 1 and continuous infusion of 5 -FU $\left(750 \mathrm{mg} / \mathrm{m}^{2}\right)$ lasting $4 \mathrm{~h}$ on days 1 to 5 , every 3 weeks. All the chemotherapy regimens were performed by a trained nurse. The selection of chemotherapy regimens for each patient was according to the recommendation of an experienced expert.

After treatment, the clinical outcomes were obtained by telephone follow-up or a return visit with the deadline of January 2014. DFS, which defined as the time from the end of chemotherapy to the first event of either recurrent disease or death, was calculated according to follow-up data.

\section{RNA extraction and real-time RT-PCR}

RNA was extracted and purified from formalin-fixed paraffin-embedded (FFPE) tissue samples of surgically resected primary CRC using an RNeasy mini kit (Qiagen, Inc.) according to the manufacturer's instructions [18]. The cDNA of ERCC1 and TS was prepared by reverse transcription from RNA [19]. The ABI PRISM 7700 Sequence Detection System (Perkin-Elmer Applied Biosystems, Foster City, CA) was used to perform TaqMan probe-based real-time PCR reactions as previously described [20-22]. Relative levels of mRNA transcripts were calculated according to the comparative $\mathrm{Ct}$ method using $\beta$-actin as an endogenous control [23].

\section{Statistical analysis}

The Cox proportional hazards model was used for univariate and multivariate analysis of prognostic factors. The variables included six continuous variables (age, duration of chemotherapy courses, interval between surgery and chemotherapy, cumulated dosage of oxaliplatin and mRNA expression levels of ERCC1 and TS) and eight categorical variables (sex, primary tumor location, tumor stage, tumor differentiation, lymph node staging, nerve invasion, vascular invasion and chemotherapy regimens). The logarithms of the TS and ERCC1 mRNA levels (logTS, $\operatorname{logERCC1)}$ were calculated for fitting normal distribution as the requirement of analysis. Dummy variables were considered for all the categorical variables. The chemotherapy regimens were used as a stratification variable in all the analyses. The backward stepwise method was used in the multivariate analysis base on the likelihood ratio statistics. Kaplan-Meier curves and log-rank tests were used for DFS analysis. Hazards ratios were used to calculate the relative risks of recurrence or death. All tests were two-sided, and $p<0.05$ was considered as statistically significant. Analyses were performed using SAS version 9.1 (Institute, Cary, NC) and SPSS 19.0 (IBM, Armonk, New York). Power was calculated using the PS Power and Sample Size Calculation, version 3.0.43 (Vanderbilt University, Nashville, TN, USA). 


\section{Results}

\section{Characteristics of patients and follow-up results}

Demographic details on the patients investigated in this study are shown in Table 1. A total of 112 Chinese patients (40 females and 72 males) aged from 32 to 75 years old (average, 52.75) were analyzed in this study. There were 61 rectum cancer patients and 38 colon cancer patients. All patients (stage IIa, 24; stage IIb, 1; stage IIIa, 3; stage IIIb, 53; stage IIIc, 31) underwent curative operation and then received 4 different chemotherapy regimens, respectively, including the standard FOLFOX-4 (20 cases), modified FOLFOX (15 cases), oral XELOX (19 cases) and conventional intravenous drip infusion (58 cases). The median follow-up duration was 36 months (ranged from 1.2 to 78 months). Relapse occurred in forty-four patients (39.3\%) and eleven patients (9.8\%) died of disease. The median DFS was 36 months (minimum: 3 months; maximum: more than 77 months) (Table 1).

\section{The mRNA expression levels of TS and ERCC1}

The median mRNA expression level of TS, relative to the housekeeping gene $\beta$-actin, was $2.86 \times 10^{-1}$ (minimum expression, $2.7 \times 10^{-2}$; maximum expression, 6.31). The median mRNA expression level of ERCC1, relative to the housekeeping gene $\beta$-actin, was $1.7 \times 10^{-3}$ (minimum, $8.57 \times 10^{-5}$; maximum, $6.7 \times 10^{-2}$ ). In addition, when analyzed by sex and age, no significant association between the TS or ERCC1 mRNA levels and these parameters was found $(P>0.05)$.

\section{Association of DFS with TS and ERCC1 mRNA levels}

For the univariate analysis, the hazard ratio (HR) for the mRNA expression levels of TS and ERCC1 (logTS: HR = $0.820,95 \% \mathrm{CI}=0.600-1.117, P=0.210 ; \operatorname{logERCC} 1: \mathrm{HR}=$ 1.054, $95 \% \mathrm{CI}=0.852-1.304, P=0.638)$ indicated that there was no significant association of DFS with the mRNA expression levels of TS and ERCC1 in Chinese CRC patients treated with oxaliplatin and 5-FU based adjuvant chemotherapy (Table 2).

Factors considered in the multivariate analyses included age, sex (male, female; reference category: female), tumor stage (stage IIa, stage IIb, stage IIIa, stage IIIb, stage IIIc; reference category: stage IIIc), tumor differentiation (high, high or medium, medium, medium or low, low; reference category: low), primary tumor location (rectum, colon; reference category: rectum), lymph node staging (N0, N1, N2; reference category: N2), vascular invasion (positive, negative; reference category: positive), nerve invasion (positive, negative; reference category: positive), interval between surgery and chemotherapy, duration of chemotherapy course, cumulated dosage of oxaliplatin as well as the mRNA expression levels of TS and ERCC1. It is clearly showed that only the tumor stage (tumor stage IIIc, reference, $P=0.083$; tumor stage $\mathrm{IIb}, \mathrm{HR}=0.240,95 \% \mathrm{CI}=$
$0.080-0.724, P=0.011$; tumor stage IIc, $\mathrm{HR}<0.0001, P=$ 0.977; Tumor stage IIIa, $\mathrm{HR}=0.179,95 \% \mathrm{CI}=0.012$ 2.593, $P=0.207$ ) entered the model in the final step and was confirmed to be the independent prognostic factor for DFS. The results indicated that the DFS in the patients with tumor stage IIb was significantly longer than that in the patients with tumor stage IIIc. In addition, there was no evidence to prove the association between the DFS and the TS and ERCC1 mRNA levels (Table 3).

The patients were divided into two groups based on the median mRNA expression levels of TS (high expression group: $>2.86 \times 10^{-1}$; low expression group: $\leq 2.86 \times 10^{-1}$ ) and ERCC1 (high expression group: $>1.7 \times 10^{-3}$; low expression group: $\left.\leq 1.7 \times 10^{-3}\right)$. The Kaplan-Meier DFS curves according to the mRNA expression levels of TS and ERCC1 all showed no significant difference between high and low expression group (TS: $P=0.264$; ERCC1: $P=0.484)$, suggesting that the mRNA expression levels of $T S$ and ERCC1 was not significantly associated with the DFS (Figure 1).

\section{Discussion}

The expression of ERCC1 and TS has been reported to be related with the clinical outcomes of patients treated with the oxaliplatin or 5-FU-based adjuvant chemotherapy $[24,25]$. Nevertheless, there was no enough evidence to prove the prognostic role of ERCC1 and TS expression in CRC patients treated with oxaliplatin and 5-FU-based adjuvant chemotherapy. Therefore, we analyzed the association of mRNA expression levels of ERCC1 and TS with DFS in Chinese patients with stage II-III CRC in this study. The results indicated no significant association between DFS and the mRNA expression levels of ERCC1 and TS, suggesting that the expression of ERCC1 and TS were not applicable as the predictive factors for DFS in Chinese stage II-III CRC patients receiving 5-FU and oxaliplatin based adjuvant chemotherapy.

However, the mRNA levels of ERCC1 and TS has been reported by Shirota $Y$ et al. to be associated with survival of 5-FU and oxaliplatin adjuvant chemotherapy in CRC patients [20]. It may be due to the difference in cancer stage and ethnicity of patients. In this study, the patients were at the stage II-III of CRC. However, the patients in the study of Shirota Y et al. [20] were at stage IV. The mRNA expression levels of ERCC1 and TS may vary with different stage of cancer. In addition, the patients were all Chinese in this study but American in the study of Shirota $Y$ et al. The gene expression profiles were different among ethnic groups [26]. Therefore, we inferred that the response of gene ERCC1 and TS to oxaliplatin and 5-FU based adjuvant chemotherapy might be different between Chinese and American patients.

Some previous studies have reported that ERCC1 expression is a predictive factor for survival after chemotherapy 
Table 1 Demographic and clinical parameters of patients $(n=112)$

\begin{tabular}{lll}
\hline Characteristics & Patients & \\
\cline { 2 - 3 } & No. & $\%$ \\
\hline
\end{tabular}

\begin{tabular}{ll}
\hline Age (years) & \\
Mean & 52.72 \\
Range & $32-75$ \\
Sex & \\
Female & 40 \\
Male & 72
\end{tabular}

Lymph node staging

$\begin{array}{ll}\text { No } & 25 \\ \text { N1 } & 49 \\ \text { N2 } & 38\end{array}$

Tumor stage

Stage lla

Stage $I 1 b$

Stage IIIa

Stage IIIb

Stage IIIC

Primary tumor location

Rectum

Colon

Vascular invasion

Positive

Negative

Nerve invasion

Positive

Negative

Chemotherapy regimen

Standard FOLFOX-4

Modified FOLFOX

Oral XELOX

Conventional intravenous drip infusion

Interval of chemotherapy and surgery

$$
\text { Within } 28 \text { days }
$$

More than 28 days

Duration of chemotherapy course

1-6 weeks
7-12 weeks
13-18 weeks
19-24 weeks
umor differentiation
High or medium

Table 1 Demographic and clinical parameters of patients ( $n=112)$ (Continued)

\begin{tabular}{lll}
\hline Medium & 64 & $57.1 \%$ \\
Medium or low & 29 & $25.9 \%$ \\
Low & 16 & $14.3 \%$ \\
Follow-up & & \\
Median & 36 months & \\
Range & $1.2-78$ months & \\
Relapse & 44 & $39.3 \%$ \\
Death & 11 & $9.8 \%$ \\
Disease free survival & & \\
Median & 36 months & \\
Range & $3-77$ months & \\
\hline
\end{tabular}

in advanced non-small cell lung cancer [27], bladder cancer [28], gastric cancer [24]. However, there was no evidence to prove the association between the mRNA expression of ERCC1 and DFS of stage II-III CRC patients receiving oxaliplatin and 5-FU based adjuvant chemotherapy in this study. It indicated that ERCC1 expression could predict clinical outcomes of chemotherapy in cancers such as non-small cell lung cancer, bladder cancer, and gastric cancer but not in stage II-III CRC.

Moreover, in this study, we found that tumor stage was a significant prognostic factor of DFS in CRC patients receiving 5-FU and oxaliplatin based adjuvant chemotherapy. It has been reported that the survival of advanced/ recurrent rectal cancers treated with 5-FU based chemotherapy was significantly associated with the tumor stage [29]. Meanwhile, another studies reported that pathologic stage significantly influenced the DFS of locally advanced rectal cancer patients after preoperative chemoradiation (5-FU or oxaliplatin) [30]. Therefore, tumor stage must be considered in the further studies for the prognostic analysis of 5-FU and oxaliplatin based adjuvant chemotherapy for CRC patients.

There were some notable limitations of this study. First, power calculation $(\alpha=0.05$; TS: power $1-\beta=0.511$; ERCC1: power $1-\beta=0.656)$ showed that the sample size was small for reliably accessing the association between TS or ERCC1 expression and DFS. Thus, more studies with larger sample size were required. Second, the followup duration was short, so that further studies must be done to verify the results of this study. Third, there were

Table 2 Univariate analyses of disease free survival according to the cox regression model

\begin{tabular}{llll}
\hline Variable & Hazard ratio & $\mathbf{9 5 \%}$ confidence interval & $\boldsymbol{P}$ \\
\hline $\log T S$ & 0.820 & $0.602-1.118$ & 0.210 \\
logERCC1 & 1.052 & $0.851-1.302$ & 0.638 \\
\hline
\end{tabular}

logTS: the logarithms of the expression level of $T S$; logERCC1: the logarithms of the expression level of ERCC1. 
Table 3 Cox regression analysis for multivariate analysis

\begin{tabular}{|c|c|c|c|}
\hline \multirow[t]{2}{*}{ Variable } & \multicolumn{3}{|c|}{ Disease free survival } \\
\hline & Hazard ratio & $95 \%$ confidence interval & $P$ \\
\hline Tumor stage (reference category: tumor stage IIIC) & & & 0.083 \\
\hline Tumor stage IIb & 0.240 & $0.080-0.724$ & 0.011 \\
\hline Tumor stage Ilc & $<0.0001$ & - & 0.977 \\
\hline Tumor stage IIla & 0.179 & $0.012-2.593$ & 0.207 \\
\hline
\end{tabular}

For the tumor stage Ilc, the hazard ratio was so small that the $95 \%$ confidence interval could not be displayed by the software.

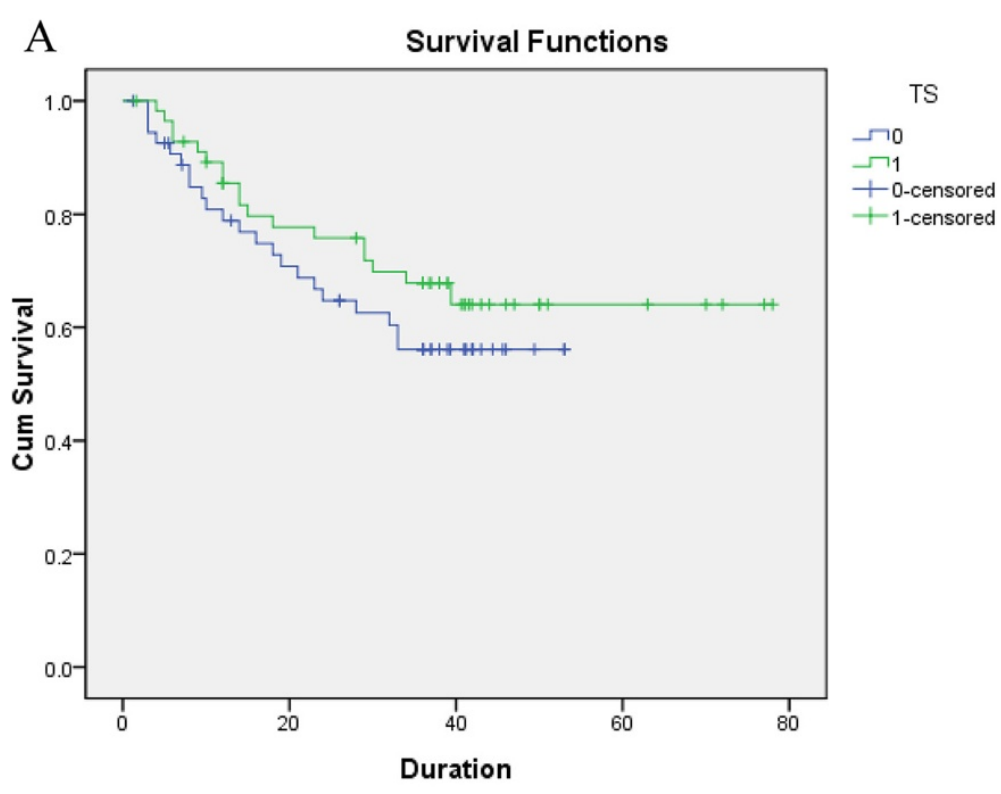

\section{B Survival Functions}

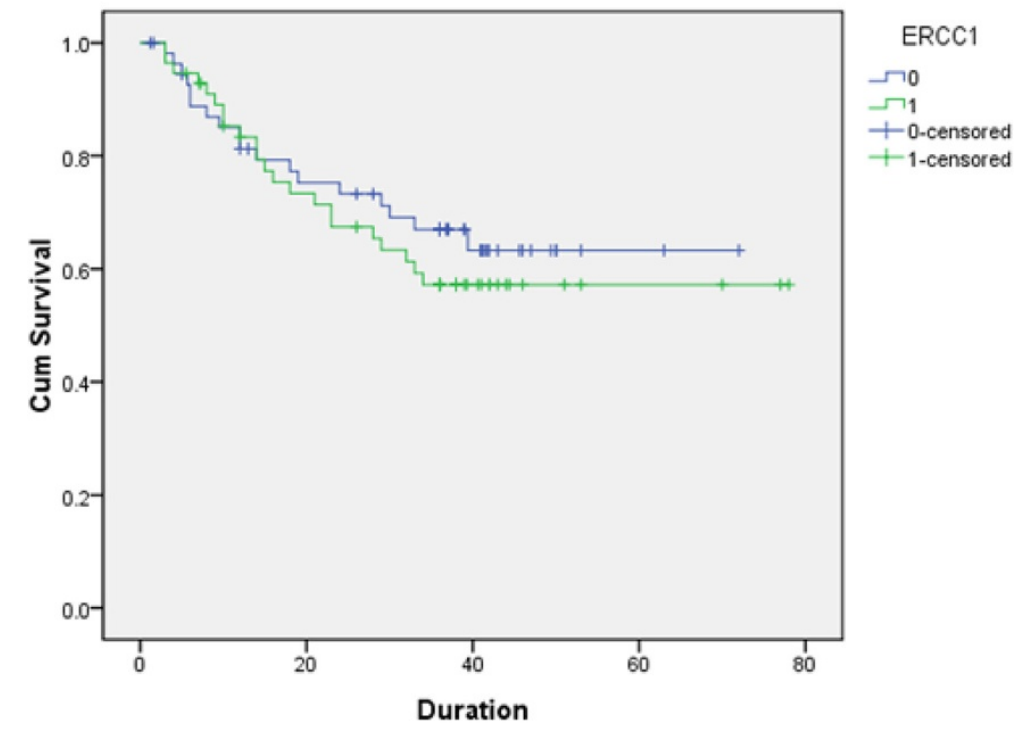

Figure 1 Disease free survival curves according to the expression level of TS and ERCC1. A: disease free survival curves according to the expression level of TS. B: Disease free survival curves according to the expression level of ERCC1. 0: low expression group; 1: high expression group. 
four chemotherapy regimens in this study, which may be a limitation for identifying association between TS or $E R C C 1$ expression and DFS in this study. In addition, the dose of 5-FU may also affect the clinical outcomes of chemotherapy, and we must investigate this potentially prognostic factor in the further studies.

\section{Conclusions}

In conclusion, our data demonstrated that mRNA expression levels of ERCC1 and TS were not significantly correlated with the DFS of Chinese stage II-III CRC patients receiving 5 -FU and oxaliplatin based adjuvant chemotherapy. It suggested that the mRNA expression levels of ERCC1 and TS were not applicable as the predictive factors for DFS in Chinese stage II-III CRC patients receiving 5-FU and oxaliplatin based adjuvant chemotherapy. Further investigations to clearly define the role of ERCC1 and TS gene expression in this setting are needed.

\section{Competing interests}

The authors declare that they have no competing interests.

\section{Authors' contributions}

$S L$ and $L Z$ participated in the design of this study, and they both performed the statistical analysis. LY carried out the study, together with LX, collected important background information, and drafted the manuscript. LP conceived of this study, and participated in the design and helped to draft the manuscript. All authors read and approved the final manuscript.

\section{Acknowledgements}

This study was supported by "Six big talent peak" in Jiangsu province, the sixth batch (NO. 1190000009). Jieping wu fund (NO. 320.6750.13115).

\section{Author details}

'Oncology, Jiangsu Tumor Hospital, NO.42 bai zi ting, Nanjing 210000, China. ${ }^{2}$ Department of Hematology, First Hospital Affiliated to Suzhou University, Suzhou 215000, China. ${ }^{3}$ Department of Pathology, Jiangsu Tumor Hospital, Nanjing 210000, China

Received: 17 January 2014 Accepted: 21 August 2014

Published: 29 August 2014

\section{References}

1. Atkin WS, Edwards R, Kralj-Hans I, Wooldrage K, Hart AR, Northover J, Parkin DM, Wardle J, Duffy SW, Cuzick J: Once-only flexible sigmoidoscopy screening in prevention of colorectal cancer: a multicentre randomised controlled trial. Lancet 2010, 375(9726):1624-1633.

2. Ferlay J, Shin HR, Bray F, Forman D, Mathers C, Parkin DM: Estimates of worldwide burden of cancer in 2008: GLOBOCAN 2008. Int J Cancer 2010, 127(12):2893-2917.

3. Jemal A, Bray F, Center MM, Ferlay J, Ward E, Forman D: Global cancer statistics. CA Cancer J Clin 2011, 61(2):69-90.

4. de Sousa E, Melo F, Colak S, Buikhuisen J, Koster J, Cameron K, de Jong JH, Tuynman JB, Prasetyanti PR, Fessler E, van den Bergh SP: Methylation of cancer-stem-cell-associated Wnt target genes predicts poor prognosis in colorectal cancer patients. Cell Stem Cell 2011, 9(5):476-485.

5. Tsuji T, Hidaka S, Sawai T, Nakagoe T, Yano H, Haseba M, Komatsu H, Shindou H, Fukuoka H, Yoshinaga M: Polymorphism in the thymidylate synthase promoter enhancer region is not an efficacious marker for tumor sensitivity to 5 -fluorouracil-based oral adjuvant chemotherapy in colorectal cancer. Clin Cancer Res 2003, 9(10):3700-3704.

6. Rubbia-Brandt L, Audard V, Sartoretti P, Roth A, Brezault C, Le Charpentier M, Dousset B, Morel P, Soubrane O, Chaussade S: Severe hepatic sinusoidal obstruction associated with oxaliplatin-based chemotherapy in patients with metastatic colorectal cancer. Ann Oncol 2004, 15(3):460-466.

7. Longley DB, Harkin DP, Johnston PG: 5-fluorouracil: mechanisms of action and clinical strategies. Nat Rev Cancer 2003, 3(5):330-338.

8. Chiara S, Nobile MT, Vincenti M, Lionetto R, Gozza A, Barzacchi MC, Sanquineti O, Repetto L, Rosso R: Advanced colorectal cancer in the elderly: results of consecutive trials with 5-fluorouracil-based chemotherapy. Cancer Chemother Pharmacol 1998, 42(4):336-340.

9. Raymond E, Chaney S, Taamma A, Cvitkovic E: Oxaliplatin: a review of preclinical and clinical studies. Ann Oncol 1998, 9(10):1053-1071.

10. Saltz LB, Clarke S, Díaz-Rubio E, Scheithauer W, Figer A, Wong R, Koski S, Lichinitser M, Yang T-S, Rivera F: Bevacizumab in combination with oxaliplatin-based chemotherapy as first-line therapy in metastatic colorectal cancer: a randomized phase III study. J Clin Oncol 2008, 26(12):2013-2019.

11. Benavides M, Pericay C, Valladares-Ayerbes M, Gil-Calle S, Massutí B, Aparicio J, Dueñas R, González-Flores E, Carrato A, Marcuello E: Oxaliplatin in combination with infusional 5 -fluorouracil as first-line chemotherapy for elderly patients with metastatic colorectal cancer: a phase II study of the Spanish cooperative group for the treatment of digestive tumors. Clin Colorectal Cancer 2012, 11(3):200-206.

12. Reed E: Nucleotide excision repair and anti-cancer chemotherapy. Cytotechnology 1998, 27(1-3):187-201.

13. Viguier J, Boige V, Miquel C, Pocard M, Giraudeau B, Sabourin J-C, Ducreux $M$, Sarasin A, Praz F: ERCC1 codon 118 polymorphism is a predictive factor for the tumor response to oxaliplatin/5-fluorouracil combination chemotherapy in patients with advanced colorectal cancer. Clin Cancer Res 2005, 11(17):6212-6217

14. Johnston PG, Lenz H-J, Leichman CG, Danenberg KD, Allegra CJ, Danenberg $P V$, Leichman $L$ : Thymidylate synthase gene and protein expression correlate and are associated with response to 5 -fluorouracil in human colorectal and gastric tumors. Cancer Res 1995, 55(7):1407-1412.

15. Peters G, Backus H, Freemantle S, Van Triest B, Codacci-Pisanelli G, Van der Wilt C, Smid K, Lunec J, Calvert A, Marsh S: Induction of thymidylate synthase as a 5-fluorouracil resistance mechanism. Biochimica et Biophysica Acta (BBA)-Mol Basis Dis 2002, 158(2):194-205.

16. Lecomte T, Ferraz J-M, Zinzindohoué F, Loriot M-A, Tregouet D-A, Landi B, Berger $A$, Cugnenc $P-H$, Jian R, Beaune P: Thymidylate synthase gene polymorphism predicts toxicity in colorectal cancer patients receiving 5-fluorouracil-based chemotherapy. Clin Cancer Res 2004, 10(17):5880-5888.

17. Kim K, Yang S, Yoon Y, Lim SB, Yu C, Kim J: Validation of the seventh edition of the American joint committee on cancer tumor-nodemetastasis (AJCC TNM) staging in patients with stage II and stage III colorectal carcinoma: analysis of 2511 cases from a medical centre in Korea. Colorectal Dis 2011, 13(8):e220-e226.

18. von Ahlfen S, Missel A, Bendrat K, Schlumpberger M: Determinants of RNA quality from FFPE samples. PLoS One 2007, 2(12):e1261.

19. Salonga D, Danenberg KD, Peters JH, DeMeester TR, Park JM, Johansson J, Skinner KA, Chandrasoma P, DeMeester SR, Tsai PI: Telomerase reverse transcriptase expression is increased early in the Barrett's metaplasia, dysplasia, adenocarcinoma sequence. J Gastrointest Surg 2000, 4(2):135-142.

20. Shirota Y, Stoehlmacher J, Brabender J, Xiong Y-P, Uetake H, Danenberg KD, Groshen S, Tsao-Wei DD, Danenberg PV, Lenz H-J: ERCC1 and thymidylate synthase mRNA levels predict survival for colorectal cancer patients receiving combination oxaliplatin and fluorouracil chemotherapy. J Clin Oncol 2001, 19(23):4298-4304.

21. Heid CA, Stevens J, Livak KJ, Williams PM: Real time quantitative PCR. Genome Res 1996, 6(10):986-994.

22. Gibson U, Heid CA, Williams PM: A novel method for real time quantitative RT-PCR. Genome Res 1996, 6(10):995-1001.

23. Schmittgen TD, Livak KJ: Analyzing real-time PCR data by the comparative CT method. Nat Protoc 2008, 3(6):1101-1108.

24. Kwon H, Roh M, Oh S, Kim S, Kim M, Kim J, Kim H: Prognostic value of expression of ERCC1, thymidylate synthase, and glutathione S-transferase P1 for 5-fluorouracil/oxaliplatin chemotherapy in advanced gastric cancer. Ann Oncol 2007, 18(3):504-509.

25. Kim S-H, Kwon H-C, Oh SY, Lee DM, Lee S, Lee J-H, Roh M-S, Kim D-C, Park $\mathrm{K}-\mathrm{J}$, Choi H-J: Prognostic value of ERCC1, thymidylate synthase, and glutathione S-transferase $\pi$ for 5 -FU/oxaliplatin chemotherapy in advanced colorectal cancer. Am J Clin Oncol 2009, 32(1):38-43. 
26. Spielman RS, Bastone LA, Burdick JT, Morley M, Ewens WJ, Cheung VG: Common genetic variants account for differences in gene expression among ethnic groups. Nat Genet 2007, 39(2):226-231.

27. Lord RV, Brabender J, Gandara D, Alberola V, Camps C, Domine M, Cardenal F, Sánchez JM, Gumerlock PH, Tarón M: Low ERCC1 expression correlates with prolonged survival after cisplatin plus gemcitabine chemotherapy in non-small cell lung cancer. Clin Cancer Res 2002, 8(7):2286-2291.

28. Bellmunt J, Paz-Ares L, Cuello M, Cecere F, Albiol S, Guillem V, Gallardo E, Carles J, Mendez P, de la Cruz J: Gene expression of ERCC1 as a novel prognostic marker in advanced bladder cancer patients receiving cisplatin-based chemotherapy. Ann Oncol 2007, 18(3):522-528.

29. Mohiuddin M, Hayne M, Regine WF, Hanna N, Hagihara PF, McGrath P, Marks GM: Prognostic significance of postchemoradiation stage following preoperative chemotherapy and radiation for advanced/recurrent rectal cancers. Curr Treat Options Oncol 2000, 48(4):1075-1080.

30. Quah HM, Chou JF, Gonen M, Shia J, Schrag D, Saltz LB, Goodman KA, Minsky BD, Wong WD, Weiser MR: Pathologic stage is most prognostic of disease-free survival in locally advanced rectal cancer patients after preoperative chemoradiation. Cancer 2008, 113(1):57-64.

doi:10.1186/1471-230X-14-154

Cite this article as: Li et al:: Association between ERCC1 and TS mRNA levels and disease free survival in colorectal cancer patients receiving oxaliplatin and fluorouracil (5-FU) adjuvant chemotherapy. BMC Gastroenterology 2014 14:154.

\section{Submit your next manuscript to BioMed Central and take full advantage of:}

- Convenient online submission

- Thorough peer review

- No space constraints or color figure charges

- Immediate publication on acceptance

- Inclusion in PubMed, CAS, Scopus and Google Scholar

- Research which is freely available for redistribution 